\title{
Status of Maternity Services in Karnali Academy of Health Sciences
}

\author{
Gautam SK, ${ }^{1}$ Dahal $M^{1}{ }^{1}$ Budha MR $^{1}$ \\ ${ }^{1}$ School of Nursing and Midwifery, Karnali Academy of Health Science, Jumla, Nepal. \\ Corresponding Author: \\ Saraswoti Kumari Gautam Bhattarai \\ Karnali Academy of Health Science, Jumla, Nepal \\ Email: saraswotigautam@gmail.com
}

\begin{abstract}
Introduction: Access to proper medical attention and hygienic conditions during delivery can reduce the risk of complications and infections for the mother and baby. Health facility-based delivery is considered a critical strategy to improve maternal health. This study aimed to identify the status of maternity service in Karnali Academy of Health Science (KAHS), Jumla.

Methods: A hospital based retrospective study was done in maternity ward of KAHS teaching hospital, Jumla Total 855 women admitted in maternity ward with obstetrical problem and labour pain were included in the study from July 16,2017 to July 16, 2018. Sampling technique was census and cases were selected from record section. Data was analyzed by using descriptive statistics.

Results: There were total 855 obstetrical cases with labour pain and other obstetrical conditions. Among them 673 $(78.71 \%)$ cases were in labour pain, $543(80.68 \%)$ had spontaneous vaginal delivery, $104(15.45 \%)$ had cesarean section. Among the 678 neonates; 650 (95.87\%) were live born baby, 28 (4.12\%) were still birth, $13(1.91 \%)$ died in neonatal period. Furthermore, among 855 obstetric cases 109(12.74\%) had obstetrical complications, and116 $(13.56 \%)$ received specific obstetrical management for complications.
\end{abstract}

Conclusions: Though there was no any maternal death in the KAHS nearly $2 \%$-neonatal death was found. Therefore, special management facility should be improved for the survival of neonates in future.

Keywords: maternal service; obstetrical complications; obstetrical management.

\section{INTRODUCTION}

Maternal health is a national health priority and improving maternal health is a major focus of the current national development plan in Nepal. ${ }^{1}$ Maternal health is the health status of women during pregnancy, childbirth, and the postpartum period, which incorporates the health care dimension of family planning, preconception, and prenatal and postnatal care to reduce maternal morbidity and mortality. ${ }^{2}$

Significant progresses have been made globally in maternal and neonatal health care, and both maternal and neonatal mortality rates have dropped in recent decades. ${ }^{3}$ The health care that a woman receives during pregnancy, at the time of delivery, and soon after delivery is important for the survival and well-being of both the mother and child. ${ }^{4}$ Labor and delivery process is an exciting, anxiety-provoking, but rewarding time for a woman and her family after successful delivery of a newborn.

The intrapartum period is the time where mothers expect more care. Taking care of a mother during delivery with no side effects is the task of a professional midwife who is trained with skills to take the responsibility of caring for mothers and babies. ${ }^{5}$ In a country like Nepal, the chances of a safe delivery are greater when the birth takes place in a health facility than at home, and increasing institutional delivery is important to reduce deaths due to pregnancy complications. ${ }^{6}$ 
Therefore the researcher is interested to identify the status of maternity services of maternity ward in Karnali Academy of Health Sciences, teaching hospital, Jumla.

\section{METHODS}

This is a hospital based retrospective study was done in maternity ward of Karnali Academy of Health Sciences teaching hospital, Jumla. A total 855 women admitted in maternity ward with obstetrical problem and labour pain were included in the study from July 16,2017 to July 16 , 2018. Sampling technique was census for the study who was admitted for obstetrical problem and condition. Cases were selected from the record of the maternity ward and record section of KAHS. Ethical approval was taken from the ethical review committee of KAHS for ethical clearance. The data was collected by using structured tool. All the information was analyzed by using descriptive statistics.

\section{RESULTS}

\begin{tabular}{|l|l|l|}
\hline \multicolumn{2}{|l|}{$\begin{array}{l}\text { Table 1. Obstetrical Characteristics of Women with Labour } \\
\text { Pain (n=673) }\end{array}$} \\
\hline Obstetrical Characteristics & Number & Percentage \\
\hline Age of Women in Year & & \\
& & \\
\hline$<20$ & 180 & 26.74 \\
\hline 20 to 35 & 474 & 70.43 \\
\hline$>35$ & 19 & 2.82 \\
\hline Parity of women & & \\
\hline Primi & 289 & 42.94 \\
\hline Multi & 272 & 40.42 \\
\hline Grand multi & 112 & 16.64 \\
\hline Week of Gestation & & \\
\hline Preterm & 47 & 6.98 \\
\hline Term & 573 & 85.14 \\
\hline Post term & 58 & 8.61 \\
\hline Among total obstetrical
\end{tabular}

Among total obstetrical cases 673 women were in labour pain. Among women with labour pain $180(26.74 \%)$ were below 20 years, $474(70.43 \%)$ were 20 to 35 years and 19 (2.82\%) were above 35 years old women. In regard to parity; 289 (42.94\%) were primiparous women, 272 (40.42\%) were multi parous women and 112 (16.64\%) were grand multi parous women. Similarly about week of gestation; $47(6.98 \%)$ were preterm, 573 $(85.14 \%)$ were term, and $58(8.61 \%)$ were post term pregnancy

\begin{tabular}{|l|l|l|}
\hline \multicolumn{4}{|l|}{ Table 2. Type of Delivery (n=673) } \\
\hline Type of delivery & Number & Percentage \\
\hline $\begin{array}{l}\text { Spontaneous Vaginal } \\
\text { Delivery }\end{array}$ & 543 & 80.68 \\
\hline Cesarean Section & 104 & 15.45 \\
\hline Vaginal Breech delivery & 19 & 2.82 \\
\hline Instrumental delivery & 13 & 1.93 \\
\hline
\end{tabular}

Among total 673 deliveries; $543(80.86 \%)$ had spontaneous vaginal delivery, 104 (15.45\%) had cesarean section, 19 (2.82\%) had vaginal breech delivery, 13 (1.93\%) had instrumental delivery.

\begin{tabular}{|l|l|l|}
\hline \multicolumn{4}{|l|}{ Table 3. Neonatal outcome $(\mathrm{n}=678)$} \\
\hline Neonatal outcome & Number & Percentage \\
\hline Live born baby & 650 & 95.87 \\
\hline Still birth & 28 & 4.12 \\
\hline Neonatal Death & 13 & 1.91 \\
\hline Sex of Neonates $(\mathrm{n}=650)$ & & \\
\hline Male & 394 & 60.62 \\
\hline Female & 256 & 39.38 \\
\hline Weight of Neonates $(\mathrm{n}=650)$ & & \\
\hline Normal Birth weight & 586 & 90.15 \\
\hline Low birth weight & 64 & 9.85 \\
\hline Among the 678 $\mathrm{n}$ & & \\
\hline
\end{tabular}

Among the 678 neonates 650 (95.87\%) were live born baby, 28 (4.12\%) were still birth, 13 $(1.91 \%)$ died in neonatal period. Regarding the sex among 650 live born baby; 394 (60.62) were male and 258 (39.38) were female. About the birth weight; 586 (90.15) had normal and $64(9.85 \%)$ had low birth weight babies.

\begin{tabular}{|l|l|l|}
\hline \multicolumn{3}{|l|}{ Table 4. Obstetrical complications (n=109) } \\
\hline Obstetrical complications & Number & Percentage \\
\hline Abortion complications & 52 & 47.70 \\
\hline Prolonged labour & 19 & 17.43 \\
\hline Molar Pregnancy & 10 & 9.17 \\
\hline Retained placenta & 9 & 8.26 \\
\hline PPH & 4 & 3.67 \\
\hline Pre-eclampsia/Eclampsia & 4 & 3.67 \\
\hline Ectopic pregnancy & 4 & 3.67 \\
\hline Ruptured Uterus & 3 & 2.75 \\
\hline Antepartum Hemorrhage & 2 & 1.83 \\
\hline Puerperal sepsis & 2 & 1.83 \\
\hline
\end{tabular}


The obstetrical complications were 109(12.74\%) among 855 obstetric cases in the maternity ward. Among 109 obstetrical complicated cases; 52(47.70\%) had abortion complications like incomplete or complete abortion, 19 (17.43\%) had prolonged labour, $10(9.17 \%)$ had molar pregnancy, 9(8.26\%) had retained placenta, 4 (3.67\%) had postpartum hemorrhage, 4 (73.67\%) had pre-eclampsia/eclampsia, 4 (3.67\%) had ectopic pregnancy, $3(2.75 \%)$ had ruptured uterus, $2(1.83 \%)$ had antepartum hemorrhage and, 2 $(1.83 \%)$ had puerperal sepsis.

\begin{tabular}{|l|l|l|}
\hline \multicolumn{3}{|l|}{ Table 5. Specific Obstetrical Management (n=116) } \\
\hline $\begin{array}{l}\text { Specific Obstetrical } \\
\text { Management }\end{array}$ & Number & Percentage \\
\hline Manual Vacuum Aspiration & 52 & 44.82 \\
\hline Blood transfused to women & 29 & 25 \\
\hline $\begin{array}{l}\text { Surgical Evacuation for molar } \\
\text { pregnancy }\end{array}$ & 10 & 8.62 \\
\hline Anti-D to Rh negative women & 10 & 8.62 \\
\hline Manual Removal of Placenta & 8 & 6.89 \\
\hline Laparotomy & 4 & 3.44 \\
\hline Obstetrical Hysterectomy & 3 & 2.58 \\
\hline
\end{tabular}

116 (13.56\%) got specific obstetrical management among 855 obstetrical cases. Among 116 cases; manual vacuum aspiration to 52 (44.82\%), blood transfused to 29 (25\%), surgical evacuation for molar pregnancy to 10 (8.62\%), anti-D for RH negative to $10(8.62 \%)$, manual removal of placenta to $8(6.89 \%)$, laparotomy to $4(3.44 \%)$, and obstetrical hysterectomy to $3(2.58 \%)$ cases.

\section{DISCUSSION}

There were 855 obstetrical cases with labour pain and other obstetrical conditions. Among them $673(78.71 \%)$ cases were in labour pain. Among women with labour pain; majority of women were 20 to 35 years that is $474(70.43 \%)$ in which contrast finding was found on study done in England that showed 58\% were between the ages of 25 and 34 years. ${ }^{7}$ In regard to parity; 289 (42.94\%) were primiparous women, 272 (40.42\%) were multi parous women and 112 (16.64\%) were grand multi parous women. And about week of gestation; most of them 573 (85.14\%) were with term pregnancy. Among total 673 deliveries; 543 (80.68\%) had spontaneous vaginal delivery, 104 (15.45\%) had cesarean section, 13 (1.92\%) had instrumental delivery. In contrast most of the women (61\%) had spontaneous vaginal births, $13 \%$ had instrumental delivery (vacuum/forceps), and $25 \%$ of women had caesarean delivery in study done in England. ${ }^{7}$ Among the 678 neonates; 650 (96.58\%) had live birth, 28 (4.12\%) still birth and 13 (1.92\%) died in neonatal period. Regarding the sex among 650 live born baby; 394 (60.62) were male and 258 (39.38) were female neonates. About the birth weight; 586 (90.15) had normal and 64 (9.85\%) had low birth weight babies.

In this study obstetrical complications were 109(12.74\%) among 855 obstetric cases in the maternity ward. Among 109 obstetrical complicated cases; 52 (47.70\%) had abortion complications 19 (17.43\%) had prolonged labour, $10(9.17 \%)$ had molar pregnancy, $9(8.26 \%)$ had retained placenta, $4(3.67 \%)$ had postpartum hemorrhage. A study done in South Sudan (2018) showed the most common obstetric complications were complicated abortions (45.7\%), followed by prolonged obstructed labour (23.2\%) and haemorrhage (16.5\%). ${ }^{8}$ Similarly, in this study 4 (3.67\%) had pre-eclampsia/eclampsia which is nearly similar to study done in tertiary hospital of Kathmandu (2013) that is 4.35\%. ${ }^{9}$ Likewise, 4 (3.67\%) had ectopic pregnancy, 3 (2.75\%) had ruptured uterus, 2 (1.83\%) had antepartum hemorrhage and, 2 (1.83\%) had puerperal sepsis. There was no any maternal death in this institution though according to Nepal Demographic Health Survey (NDHS, 2016) the maternal mortality ratio (MMR) for Nepal is 239 deaths per 100,000 live births. ${ }^{10}$ Among 855 obstetrical cases 116 (13.56\%) received specific obstetrical management. Among 116 cases; manual vacuum aspiration to 52 (44.82\%), blood transfused to 29 (25\%), surgical evacuation for molar pregnancy to $10(8.62 \%)$, anti-D for RH negative to 10 (8.62\%), manual removal of placenta to $8(6.89 \%)$, laparotomy to $4(3.44 \%)$, obstetrical hysterectomy to $3(2.58 \%)$ cases. 


\section{CONCLUSIONS}

Among the total obstetrical cases majority of women were in labour pain and only very few women had obstetrical complications. Though there was no any maternal death in this institution less than one fourth neonatal death was found. Therefore, special management facility should be improved for the survival of neonates in future.

\section{ACKNOWLEDGEMENT}

The authors would like to acknowledge to staffs of Maternity ward and record section of KAHS for the study and to institutional review committee (IRC) for ethical clearance.

\section{Conflict of Interest: None}

\section{REFERENCES}

1. Government of Nepal. The Tenth Plan 2002-2007. National Planning Commission, His Majesty's Government of Nepal, Kathmandu. 2002

2. World health Organization (WHO). Fact sheet maternal health Topic ( 2015)

3. WHO. Trends in Maternal Mortality 1990-2008. 3.6 Million NeonatalDeaths-What Is Progressing and What Is Not? Geneva: (2010)

4. DoHP, New ERA,ICF International. Nepal Demographic and Health Survey 2011. Kathmandu Nepal: Ministry of Health and Population, New ERA, and ICF International, Calverton, Maryland,USA. 2012

5. Afaya A, Yakong VN, Afaya RA, Salia SM, Adatara P, Kuug AK, Nyande FK. A Qualitative Study on Women's Experiences of Intrapartum Nursing Care at Tamale Teaching Hospital (TTH), Ghana. Journal of caring sciences. 2017 Dec;6(4):303

6. Campbell OM, Graham WJ. Strategies for reducing maternal mortality: getting on with what works. Lancet. 2006;368(9543):1284-99

7. Rowlands IJ and RedshawM .Mode of birth and women's psychological and physical wellbeing in the postnatal period: BMC Pregnancy and Childbirth 2012, 12:138
8. Bayo P, Itua I, Francis SP, Boateng K, Tahir EO, Usman A. Estimating the met need for emergency obstetric care (EmOC) services in three payams of Torit County, South Sudan: a facility-based, retrospective crosssectional study: BMJ Open 2018;8:e18739

9. Gautam (Bhattarai) SK, Paudel K, Silwal K.Management and Outcome of Pre-eclampsia/ Eclampsiaamong patient admitted in maternity ward in tertiary hospital: Journal of Institute of Medicine, August, 2013, 35:2

10. Ministry of Health, Nepal; New ERA; and ICF. 2016 Nepal Demographic and Health Survey Key Findings. Kathmandu, Nepal: Ministry of Health Nepal. 2017 